\title{
Sex differences and estrous cycle changes in hippocampus-dependent fear conditioning
}

\author{
ETAN J. MARKUS and MAJA ZECEVIC \\ University of Connecticut, Storrs, Connecticut
}

\begin{abstract}
Male and naturally cycling female rats were tested in a fear conditioning paradigm that encompassed both hippocampus-dependent and -independent components. The females were both conditioned and tested for retention at the same stage of the estrous cycle, during either estrus or proestrus. Male rats followed a regime similar to that for the female rats. Approximately 2 weeks after conditioning, the animals were examined for retention of the spatial context and of an explicitly paired conditioning tone. All animals showed a similar degree of conditioning to the tone. However, female proestrous rats showed less spatial-contextual conditioning than did male or estrous female rats. These results suggest that the changes found during the proestrous part of the cycle are related to hippocampal information processing and not to general changes in learning ability, to shock sensitivity, or to state-dependent learning. The results are discussed and related to previous findings regarding estrous cycle changes in behavior, anatomy, and physiology.
\end{abstract}

It has been reported that male rodents perform better than females on a variety of land mazes (Beatty, 1984; Dawson, 1972; Gaulin \& Fitzgerald, 1989; Joseph, Hess, \& Birecree, 1978; Stewart, Skvarenina, \& Pottier, 1975; Williams, Barnett, \& Meck, 1990), as well as on the Morris water maze (Frye, 1994; Warren, Wilson, \& Nadel, $1990)$ and in the spatial-contextual fear conditioning task (Maren, De Oca, \& Fanselow, 1994). A large body of evidence indicates hippocampal involvement in some of these tasks (e.g., Jarrard, 1993; Kesner, Bolland, \& Dakis, 1993; Kim \& Fanselow, 1992; Phillips \& LeDoux, 1992; Sutherland \& Rudy, 1989). Thus the behavioral findings may be related to, among other things, sex differences found in hippocampal size (Jacobs, Gaulin, Sherry, \& Hoffman, 1990; Pfaff, 1966; Roof \& Havens, 1992), number of hippocampal neurons (Madeira et al., 1992), and changes in hippocampal morphology as a consequence of gonadal hormone administration (see Gould, Woolley, $\&$ McEwen, 1991, for a review). These changes include synaptic structural reorganization similar to that found during development (see, e.g., Markus \& Petit, 1987; Markus, Petit, \& LeBoutiller, 1987).

In addition to general sex differences, hippocampal morphological changes are seen across the female rat's natural 4- to 5-day estrous cycle, especially during the 24-h period between the peak of estradiol (proestrus) and the following low-estradiol part of the cycle (estrus). During proestrus, there is approximately a $30 \%$ increase

\footnotetext{
Special thanks to M. L. Anderson for assistance in coding behavior and to B. Sachs for helpful comments on the manuscript. This research was supported by University of Connecticut Research Foundation Grant 441713 to E.J.M. Correspondence should be addressed to E. J. Markus, Behavioral Neuroscience Division, Department of Psychology, University of Connecticut, Storrs, CT 06269 (e-mail: markus@psych.psy.uconn.edu).
}

in synaptic density in the CA1 region of the hippocampus (Woolley, Gould, Frankfurt, \& McEwen, 1990; Woolley \& McEwen, 1992), paralleling changes in physiological activity (Kawakami, Teresawa, \& Ibuki, 1970) and increased plasticity (seizure induction--Teresawa \& Timiras, 1968; long term potentiation--Humphreys, Warren, Juraska, \& Greenough, 1994; Korol et al., 1994; Warren, Humphreys, Juraska, \& Greenough, 1995). These increases in synaptic density and in plasticity during proestrus are accompanied by a decrease in the water maze ability of the rats (Frye, 1994; Warren \& Juraska, 1995). Thus the data seem to indicate an inverse relationship, with increases in hippocampal anatomy and plasticity being accompanied by decreases in hippocampaldependent behavioral ability. The water maze data are difficult to interpret, however, because it is hard to distinguish between specific hippocampal-related changes and other general behavioral (see, e.g., Archer, 1975) and physiological (e.g., Wade, 1976) changes found over the course of the estrous cycle. Water maze performance could be affected by estrous cycle changes in factors such as motor or swim ability, body fat composition, or thermoregulation. In the present experiment, we examined whether the proestrus-related behavioral change found on the water maze task is also found in another hippocampus-dependent behavior, contextual fear conditioning. An advantage of using a fear conditioning paradigm is that it allows one to differentiate between general estrous cycle behavioral changes and those that are hippocampus specific.

Fear conditioning involves pairing a neutral (conditioned) stimulus such as a tone with an aversive unconditioned stimulus, usually a footshock. The neutral stimulus, through its association with the aversive stimulus, acquires aversive properties and comes to evoke responses characteristically elicited by the noxious stimu- 
Table 1

Experimental Procedure

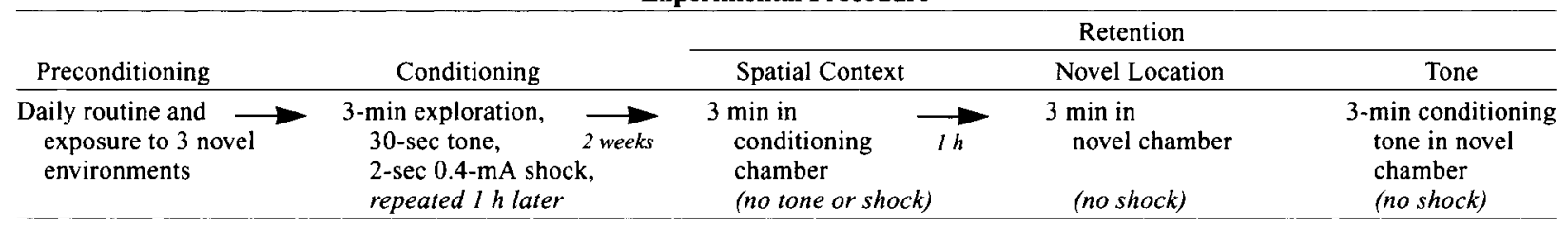

lus. Thus a tone that has previously been paired with a footshock evokes a "fear" response, which is characterized by an array of responses, including the release of adrenal hormones, increased heart rate, startle, defecation, and freezing (see Davis, 1992; Phillips \& LeDoux, 1992). This freezing response (i.e., suppression of movement) is one of the species-specific defensive responses characteristic of rats (Bolles, 1970), and it is how rats respond to an inescapable footshock situation (Blanchard, Fukunaga, \& Blanchard, 1976). Because the freezing and other fear responses are not evoked by the tone before the temporal pairing of the tone with the footshock, they are referred to as learned or conditioned emotional responses.

In addition to being elicited by a tone, conditioned fear responses can be elicited by placing the animal back into the chamber in which the footshock has previously been experienced. In this situation, the conditioned fear responses are evoked not by a stimulus that has explicitly and predictably been paired with the footshock (the tone), but instead by some combination of the various spatial-contextual stimuli that are present when the footshock occurs and that remain present when the animal is returned to the chamber (e.g., Stoehr, Markus, Nadel, \& Wenk, 1994). These two types of conditioning-that to the explicit stimulus (tone) and that to the context - are dependent on different brain structures. Recognition of the background context or place is related to hippocampal function, whereas recognition of an explicit stimulus (tone) remains intact even in animals with hippocampal lesions (Kim \& Fanselow, 1992; Phillips \& LeDoux, 1992). In a recent study, Maren et al. (1994) found differences between male and female rats in fear conditioning. Male rats showed a stronger fear response than females did when both were tested for the retention of the hippocampal-dependent spatial-contextual conditioning, but no sex differences were found for the retention of the nonhippocampal-dependent conditioning to an explicit stimulus (a tone).

In the present study, we examined (1) whether the sex differences and proestrus-related behavioral deficits reported are related to state-dependent learning (females trained at one stage but tested at a different stage of the cycle); (2) whether they are limited only to tasks in which an operant motor response is required (i.e., the water maze) or are also found in a hippocampus-dependent task based on classical conditioning; and (3) whether other nonhippocampal abilities are also affected by the estrous cycle.

Male and naturally cycling female rats were tested in a fear conditioning paradigm that encompassed both hippocampus-dependent and -independent components.
The females were conditioned and tested for retention at the same stage of the estrous cycle, during either estrus or proestrus. Some of these data have been presented in abstract form (Markus, Zecevic, \& Anderson, 1996).

\section{METHOD}

\section{Subjects}

Twelve male and 24 female 4- to 5 -month-old Fischer 344 rats (Harlan Sprague-Dawley) were tested. The males and females were housed along opposite walls in a single room $(4.5 \times 4.5 \mathrm{~m})$, with a 12:12-h light:dark cycle (lights off at $1700 \mathrm{~h}$ ). During the conditioning and behavioral testing phases of the experiment, the animals were singly housed in transparent plastic tubs $(43 \times 23 \times$ $19 \mathrm{~cm}$ ). Approximately 1 month before conditioning, a daily routine was established in which all animals were weighed and given an anal probe (males) or lavaged (females), between 1200 and $1400 \mathrm{~h}$. The lavaged vaginal epithelium cells were examined under a light microscope to determine the animal's estrous cycle phase. Animals with few leucocytes and many large round nucleated cells were determined to be in proestrus; animals with predominantly cornified cells and no leucocytes were determined to be in estrus (Schwartz \& Hoffman, 1972).

All conditioning and retention sessions were conducted during the light cycle between 1300 and $1700 \mathrm{~h}$. The determination of cycle stage for conditioning and retention was based on the results of the daily lavage and was verified by a lavage on the following day (animals in proestrus progress to estrus; animals in estrus progress to metestrus). Only animals showing a regular estrous cycle and whose cycle stage was verified on the following day were used in the experiment.

\section{Behavior}

In order to adapt the rats to the general experimental procedure, during the preconditioning period the animals were placed in three different novel locations for 3-5 min in each. On the day of conditioning, the rats were placed in a shock chamber $(28 \times 21 \times$ $21 \mathrm{~cm}$, Med Associates). After a 3-min exploratory period, a 30sec tone was delivered $(70 \mathrm{~dB})$, followed by a 2 -sec $0.4-\mathrm{mA}$ current from a shock generator/scrambler (Lafayette Instruments), after which the animals were returned to the animal facility. This procedure was repeated $1 \mathrm{~h}$ later. Spatial-contextual retention was tested approximately 2 weeks later by placing the animals back in the original conditioning chamber for $3 \mathrm{~min}$; however, no tone or shock was administered. One hour after the spatial-contextual retention test, the rats were placed in a novel chamber in a novel room. The novel chamber differed from the conditioning chamber in size, in wall and floor composition, and in the cleaning agent used between animals. After a 3-min period in this novel chamber,

Table 2

Retention Interval (in Days) for the Three Groups of Animals

\begin{tabular}{lcccc}
\hline Sex/Stage of Estrous Cycle & Mean & Maximum & Minimum & $n$ \\
\hline Estrous females & 15.08 & 16 & 14 & 11 \\
Proestrous females & 15.17 & 17 & 14 & 12 \\
Males & 15.27 & 16 & 14 & 11 \\
\hline
\end{tabular}




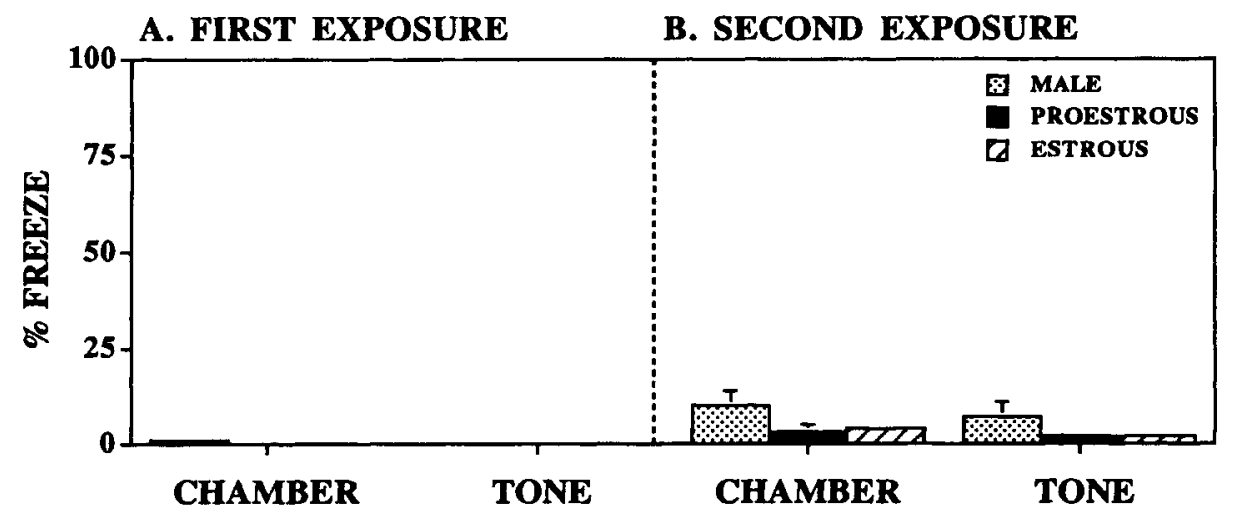

Figure 1. The amount of freezing $(M+S E M)$ by the animals in response to exposure to the chamber and tone. (A) First exposure to the chamber $(3 \mathrm{~min})$ and followed by a tone $(30 \mathrm{sec})$. The animals show a large degree of exploration with almost no freezing. The session ended with a 2-sec 0.4$\mathrm{mA}$ shock. (B) Second exposure to the chamber $(3 \mathrm{~min})$ and tone $(30 \mathrm{sec})$ approximately $60 \mathrm{~min}$ after the first shock. The second session also terminated with a $2-\sec 0.4-\mathrm{mA}$ shock.

the animal received the conditioned tone for $3 \mathrm{~min}$ (see Table 1) The conditioning and retention sessions were always conducted during the same phase of the estrous cycle for a given female rat; male rats were tested for retention after an interval similar to that for the females.

\begin{abstract}
Analysis
The animals were videotaped during the conditioning and retention sessions. The amount of motion displayed by the rats during these sessions was coded every 6 sec by two observers blind to the animal's estrous cycle stage. ${ }^{1}$ The animals were coded as freezing (lack of any non-respiratory-related movement) or active (all other behaviors, including rearing and grooming). A one-way analysis of variance was carried out for each session, comparing the three groups (male, proestrous, and estrous rats).
\end{abstract}

\section{RESULTS}

Animals were tested for retention at the same stage of the cycle as that during which they were conditioned; this constraint prevented a test of retention at a fixed interval for all animals. As can be seen in Table 2, retention was examined 14-17 days after conditioning, and there was no significant difference in the retention interval for the different groups $[F(2,31)=0.36, p>.10]$. One male rat and 1 estrous female rat had to be discarded, owing to technical problems (shock generator and tone generator, respectively). In addition, because of technical problems with the video equipment, the context retention data from 2 male rats could not be scored. An examination of the daily estrous cycle records in the days preceding and following the day of conditioning showed no effect of the conditioning episode on the animals' estrous cycle.

As can be seen in Figure 1 A, all animals showed robust exploration and movement (i.e., no freezing) when initially placed in the conditioning chamber and when first exposed to the conditioning tone. A similar response was seen when the animals were placed a second time into the chamber $1 \mathrm{~h}$ after receiving the first conditioning shock (Figure 1B). It should be noted that although there was a qualitative change in the animals' move- ments during this second exposure (less locomotion and more grooming and rearing), there was still very little freezing (lack of any non-respiratory-related movement).

Two weeks after conditioning, the animals were placed back into the conditioning chamber. The animals showed a substantial amount of freezing response, with a significant main effect of sex/estrous cycle $[F(2,29)=3.45$, $p<.05]$. A Duncan post hoc test revealed that proestrous rats had a significantly lower fear response (less freezing) than did males or estrous females (both $p s<.05$; Figure 2 ).

To examine the response of the animals to simply being taken out of their home cage (a general fear response), the animals were placed in a novel environment very different from the conditioning chamber. All animals showed some freezing in the novel environment (all displayed about $25 \%$ freezing; Figure 3 ); however, there were no sex-or estrous-cycle-related differences $[F(2,31)=$ $0.36, p>.10]$.

After a 3-min period in the novel chamber, the conditioning tone was given; all animals responded with an in-

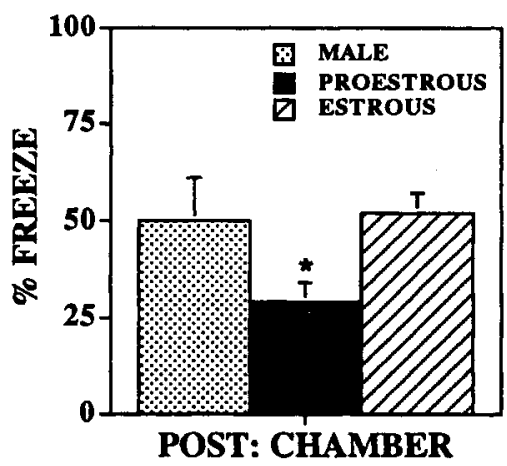

Figure 2. The amount of freezing by the animals in response to being placed back into the conditioning chamber approximately 2 weeks after the two conditioning sessions. Proestrous rats showed a significantly lower freezing response than did males or female rats in estrus. 


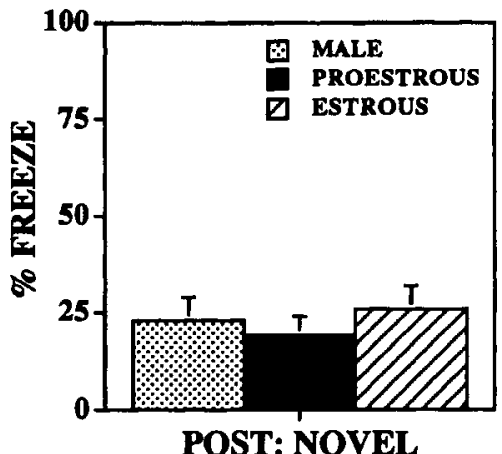

Figure 3. The amount of freezing by the animals in response to being placed in a novel environment. Although all animals displayed some freezing, there were no differences among groups.

creased amount of freezing (about $60 \%$ freezing; Figure 4); however, there were no sex- or estrous-cyclerelated differences between the groups $[F(2,31)=0.98$, $p>.10]$.

\section{DISCUSSION}

Rats conditioned and tested during the proestrous stage of the cycle showed a significantly reduced amount of spatial-contextual fear conditioning in comparison with males or female estrous rats. There was no difference between animals in conditioning to an explicit stimulusthe tone. Thus, the deficit in fear conditioning was specific to the retention of the chamber/place/situation in which the animals were conditioned. This reduction in recognition of spatial-contextual environment is also apparent if we compare the responses of the proestrous rats to being placed back into the conditioning chamber (Figure 2) and to being placed into a novel environment (Figure 3). Note that unlike the males and estrous rats, the proestrous rats do not show a differential response to the familiar and unfamiliar environments; that is, they display a similar amount of freezing in both.

\section{Hippocampus-Specific Versus \\ General Estrous Cycle Effects}

One of the problems in investigating estrous cycle effects on hippocampal processing is the difficulty of distinguishing between general effects and those specific to the hippocampus. One potential issue is whether the estrous cycle changes the animal's shock sensitivity or the manner in which the animal responds to a shock. In the present experiment, the proestrous animals were similar to males and estrous females in their fear response to the conditioned tone. This implies that all animals perceived the shock in a similar manner; that is, pain sensitivity was equal for all groups. This interpretation of the results is in agreement with previous findings showing that although there are changes in shock sensitivity across the entire estrous cycle, there are no differences in sensitiv- ity between the estrous and proestrous stages of the cycle (Drury \& Gold, 1978; Farr et al., 1995; Frye, Bock, \& Kanarek, 1992). A second potential confound is the fact that all the animals were tested in the same order, so that the context retention trial could have served as a reminder for the conditioned tone. If this were the case, animals remembering the context better (i.e., males and estrous females), should also have shown a stronger response to the tone. This did not occur; in fact, there was a tendency for both female groups (estrous and proestrous) to show more freezing to the tone than did the males. A third potential issue consists of possible differences in motor activity among groups, whereby findings of reduced freezing during contextual retention could reflect a nonspecific reduction in activity levels during proestrus. However, the proestrous animals showed the same level of activity as did the other animals when originally placed in the conditioning chamber, as well as the same mild fear response postconditioning when later placed into the novel chamber. Thus, the differences found in the freezing response to the conditioned context cannot be attributed to a nonspecific difference in motor activity.

The lack of difference in activity levels is in contrast with previous reports of sex- and estrus-related changes in motor activity in an open field or on a running wheel (e.g., Archer, 1975; Becker, Snyder, Miller, Westgate, \& Jenuwine, 1987) and may reflect the specific conditions used in the fear conditioning paradigm. In the present study, the rats were placed in a very small chamber for only a few minutes, which may have constrained the amount and type of exploration that they exhibited. Evidently the present paradigm minimized the general sex and estrous cycle effects on motor activity and indicated changes specific to spatial-contextual processing.

The specific type of information processing taking place during the spatial-contextual task is unclear. Phillips and LeDoux (1994) have shown that hippocampal lesions interfere with background contextual conditioning (as in the present study) but have no effect when the context is

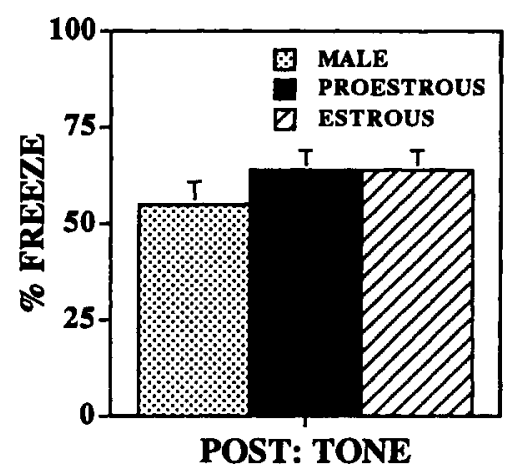

Figure 4. The amount of freezing by the animals in response to the conditioning tone in the novel environment. Although all animals showed a great deal of freezing, there were no differences among groups. 
the only element to be conditioned. Future research should examine to what degree the estrous cycle changes found in the present study were related to the content of contextual information processed (e.g., spatial vs. tactile features of the chamber), rather than to the type of processing taking place (background vs. explicit information).

\section{Estrous Cycle and State-Dependent Learning}

Overton (1964) and others showed the dependence of retention on the similarities between the learning and retention sessions. Recently, state-dependent retention has been shown when the rats' hormonal state was used as the independent variable (Costanzo, Riccio, \& Kissinger, 1995). Thus, some of the early findings of sex differences in land and water mazes could have been the result of state dependence. Female rats may have shown deficits because they were trained at one part of the cycle but tested for retention at a different part of the cycle. This could also account for deficits on tasks that encompassed a long training period, since the females' internal state (estrous cycle) varied over the course of the training. In the present study, both the learning and the retention phases were conducted at the same part of the estrous cycle. Consequently, the results indicate the presence of an estrous cycle effect on spatial-contextual conditioning independent of state-dependence effects.

\section{Fear Conditioning, Radial Maze, Water Maze, and Hippocampal Processing}

Sex differences. The present findings of a deficit in spatial-contextual fear conditioning during proestrus support and extend other findings of an overall deficit in female as opposed to male rats in spatial-contextual fear conditioning (Maren et al., 1994). Although the findings of proestrus-related deficits in spatial-contextual fear conditioning are evident, the interpretation of the findings is more complex. Spatial-contextual fear conditioning has been shown to be hippocampus dependent (Kim \& Fanselow, 1992; Phillips \& LeDoux, 1992), as are the water maze (see, e.g., Morris, Garrud, Rawlins, \& O'Keefe, 1982) and spatial land mazes (e.g., Jarrard, 1993). To gain a better understanding of estrous-cyclerelated changes in hippocampal processing, it is imperative to compare data gathered on these three types of tasks. Although all three tasks are similar in their dependence on the intact hippocampus, they differ in many other respects. As discussed above, one of the problems in investigating estrous cycle effects on hippocampal processing is the difficulty of distinguishing between general effects and those specific to the hippocampus. Thus, water maze performance could theoretically be affected by estrous cycle changes in motor or swim ability, body fat composition, or thermoregulation (for some general physiological changes, see Wade, 1976). Similarly, the traditional radial arm maze incorporates an appetitive task and could be affected by the changes in feeding behavior over the estrous cycle (see, e.g., Wade, 1976) or findings of estradiol-related taste aversion conditioning (Ganesan, 1994). Although there have been some reports of general sex differences on the water maze (e.g., Roof, 1993; Warren et al., 1990) and spatial radial mazes (e.g., Luine \& Rodriguez, 1994; Roof, 1993), there are other reports of no sex differences (e.g., water maze, Bucci, Chiba, \& Gallagher, 1995; 8-arm radial maze, Juraska, Henderson, \& Muller, 1984; van Haaren, Wouters, \& van de Poll, 1987). These data are difficult to interpret, since differences found could have been due to the effect of state-dependent learning, whereas a lack of differences could be due to collapsing female rats at different stages of the cycle into one group.

Estrous cycle effects. In water maze studies in which the stage of the estrous cycle is monitored, deficits are found during proestrus (Frye, 1994; ${ }^{2}$ Korol et al., 1994; Warren \& Juraska, 1995), although in a recent study Berry, McMahan, and Gallagher (1996), found no estrous cycle effects on this task. This may have been due to the sex-related differential effects of pretraining on the performance of the water maze task (Perrot-Sinal, Kavaliers, \& Ossenkopp, 1996). The assessment of the radial arm maze learning ability of naturally cycling rats is more complex, owing to the prolonged training needed on this task. One approach is to examine the prevalence of errors of animals on this task on the different days of the estrous cycle. Using this procedure, Blasberg, Stackman, Langan, and Clark (1996) found that although latencies increased during proestrus, there were no differences in errors across the estrous cycle. A different approach is to examine gonadectomized females with and without estrogen replacement. Under certain conditions, estradiol treatment enhanced radial maze performance (Luine, Rentas, Sterbank, \& Beck, 1996; Williams, 1996), and under others, it had no effect (Luine et al., 1996; Luine \& Rodriguez, 1994; Williams, 1996). Recently it has been reported (D. L. Korol, personal communication) that in naturally cycling rats there is an increased tendency during proestrus to use a spatial rather than a response strategy in solving a land based appetitive task.

The present fear conditioning results, together with findings obtained by others from the water maze task, indicate a deficit in hippocampal learning during proestrus. The reports of others from the use of the radial maze are more difficult to interpret, but they may indicate, if anything, an improved spatial ability during proestrus. Future studies utilizing the water and 8-arm radial mazes should incorporate nonhippocampal control tasks to examine the general effects of the estrus cycle on these types of mazes. One important difference between these tasks is the fact that the former are spatial-aversive, whereas the latter is a spatial-appetitive task. A way in which this question could be investigated further would be to examine the learning ability of naturally cycling rats on a task that combines elements from these different tasks. For example, estrous cycle effects on the traditional appetitive land version could be compared with a water version of the radial maze, or with a land-based version of the water maze.

The dynamic changes in hippocampal anatomy and physiology over the estrous cycle should conceivably be 
reflected by changes in hippocampal function and consequently in the animal's ability to perform a hippocampusrelated behavior. Examining the changes in hippocampalrelated abilities over the estrous cycle may provide data on the critical elements needed for effective hippocampal information processing. Although the radial maze data are still inconclusive, it seems that at least on hippocampaldependent aversive tasks there is a decline in behavioral ability during the period of increased hippocampal synaptic density and plasticity. This may indicate that the relationship between anatomical connectivity and plasticity to behavior is more complex than previously thought and must be examined further.

\section{REFERENCES}

ARCHER, J. (1975). Rodent sex differences in emotional and related behavior. Behavioral Biology, 14, 451-479.

BEATTY, W. W. (1984). Hormonal organization of sex differences in play fighting and spatial behavior. In G. J. de Vries, J. P. C. Debruin, H. B. M. Uylings, \& M. A. Corner (Eds.), Sex differences in the brain (pp. 315-330). Amsterdam: Elsevier.

Becker, J. B., Snyder, P. J., Miller, M. M., Westgate, S. A., \& JENUWINE, M. J. (1987). The influence of estrous cycle and intrastriatal estradiol on sensorimotor performance in the female rat. Pharmacology, Biochemistry \& Behavior, 27, 53-59.

Berry, B., McMahan, R., \& Gallagher, M. (1996). The effects of estrogen on performance of a hippocampal-dependent task. Society for Neuroscience Abstracts, 22, 1386.

Blanchard, R. J., Fukunaga, K. K., \& Blanchard, D. C. (1976). Environmental control of defensive reactions to footshock. Bulletin of the Psychonomic Society, 8, 129-130.

Blasberg, M. E., Stackman, R. W., Langan, C. J., \& Clark, A. S. (1996). Dynamics of working memory across the estrous cycle. Society for Neuroscience Abstracts, 22, 1386.

Bolles, R. C. (1970). Species-specific defensive reactions and avoidance learning. Psychological Review, 71, 32-48.

Bucci, D. J., Chiba, A. A., \& Gallagher, M. (1995). Spatial learning in male and female Long-Evans rats. Behavioral Neuroscience, 109, 180-183

Costanzo, D. J., Riccio, D. C., \& KissingeR, S. (1995). State-dependent retention produced with estrus in rats. Physiology \& Behavior, 57, 1009-1011.

Davis, M. (1992). The role of the amygdala in fear and anxiety. Annual Review of Neuroscience, 15, 353-375.

Dawson, J. L. M. (1972). Effects of sex hormones on cognitive style in rats and men. Behavioral Genetics, 2, 21-42.

DruRY, R. A., \& GOLD, R. M. (1978). Differential effects of ovarian hormones on the reactivity to electric footshock in the rat. Physiology \& Behavior, 20, 187-191.

Farr, S. A., Flood, J. F., Scherrer, J. F., Kaiser, F. E., Taylor, G. T., \& MoRLEY, J. E. (1995). Effects of ovarian steroids on footshock avoidance learning and retention in female mice. Physiology \& Behavior, 58, 715-723.

FRYE, C. A. (1994). Estrus-associated decrements in water maze task are limited to acquisition. Physiology \& Behavior, 57, 5-14.

Frye, C. A., Bock, B. C., \& KanareK, R. B. (1992). Hormonal milieu affects tailflick latency in female rats and may be attenuated by access to sucrose. Physiology \& Behavior, 52, 699-706.

Ganesan, R. (1994). The aversive and hypophagic effects of estradiol. Physiology \& Behavior, 55, 279-285.

Gaulin, S. J. C., \& Fitzgerald, R. W. (1989). Sexual selection for spatial-learning ability. Animal Behaviour, 37, 322-331.

Gould, E., Woolley, C. S., \& MCEWEN, B. S. (1991). The hippocampal formation: Morphological changes induced by thyroid, gonadal and adrenal hormones. Psychoneuroendocrinology, 16, 67-86.

Humphreys, A. G., Warren, S. G., Juraska, J. M., \& Greenough, W. T. (1994). Estrous cycle regulates synaptic plasticity: Enhanced
LTP sensitivity in proestrus rats. Society for Neuroscience $A b$ stracts, 20, 802 .

Jacobs, L. F., Gaulin, S. J. C., Sherry, D. F., \& Hoffman, G. E. (1990). Evolution of spatial cognition: Sex-specific patterns of spatial behavior predict hippocampal size. Proceedings of the National Academy of Sciences, 87, 6349-6352.

JARRARD, L. E. (1993). On the role of the hippocampus in learning and memory in the rat. Behavioral \& Neural Biology, 60, 9-26.

Joseph, R., Hess, S., \& Birecree, E. (1978). Effects of hormone manipulations and exploration on sex differences in maze learning. Behavioral Biology, 24, 364-377.

Juraska, J. M., Henderson, V., \& Muller, J. (1984). Differential rearing experience, gender, and radial maze performance. Developmental Psychobiology, 17, 209-215.

KawaKami, M., Teresawa, E., \& IbuKi, T. (1970). Changes in multiple unit activity in the brain during the estrous cycle. Neuroendocrinology, 6, 30-48.

Kesner, R. P., Bolland, B. L., \& Dakis, M. (1993). Memory for spatial locations, motor responses, and objects: Triple dissociation among the hippocampus, caudate nucleus, and extrastriate visual cortex. Experimental Brain Research, 93, 462-470.

KIM, J. J., \& FANSELOW, M. S. (1992). Modality-specific retrograde amnesia of fear. Science, 256, 675-677.

Korol, D. L., Unick, K., Goosens, K., Crane, C., Gold, P. E., \& Foster, T. C. (1994). Estrogen effects on spatial performance and hippocampal physiology in female rats. Society for Neuroscience Abstracts, 20, 1436.

Luine, V N., Rentas, L., Sterbank, L., \& Beck, K. (1996). Estradiol effects on rat spatial memory. Society for Neuroscience Abstracts, 22, 1387.

LUINE V. [N.], \& RodRiguez, M. (1994). Effects of estradiol on radial arm maze performance of young and aged rats. Behavioral \& Neural Biology, 62, 230-236.

Madeira, M. D., Sousa, N., Lima-Andrade, M. T., Calheiros, F., Cadete-Leite, A., \& Paula-Barbosa, M. M. (1992). Selective vulnerability of the hippocampal pyramidal neurons to hypothyroidism in male and female rats. Journal of Comparative Neurology, 322, 501-518.

Maren, S., De Oca, B., \& Fanselow, M. S. (1994). Sex differences in hippocampal long-term potentiation (LTP) and Pavlovian fear conditioning in rats: Positive correlation between LTP and contextual learning. Brain Research, 661, 25-34.

Markus, E. J., \& Petit, T. L. (1987). Neocortical synaptogenesis, aging, and behavior: Lifespan development of the motor-sensory system in the rat. Experimental Neurology, 96, 262-278.

Markus, E. J., Petit, T. L., \& LeBoutiller, J. C. (1987). Synaptic structural change during development and aging. Developmental Brain Research, 35, 239-248.

Markus, E. J., Zecevic, M., \& Anderson, M. L. (1996). Contextual fear conditioning across the estrous cycle. Society for Neuroscience Abstracts, 22, 1134.

Morris, R. G. M., Garrud, P., Rawlins, J. N. P., \& O’Keefe, J. (1982). Place navigation impaired in rats with hippocampal lesions. Nature, 297, 681-683.

OVERTON, D. A. (1964). State dependent or dissociated learning produced with pentobarbital. Journal of Comparative Physiology \& Psychology, 57, 3-12.

Perrot-Sinal, T. S., Kavaliers, M., \& OssenkopP, K.-P. (1996). Spatial learning in rats-The effect of sex and prior familiarization with non-spatial aspects of the task. Society for Neuroscience $A b$ stracts, 22, 1387.

PfAFF, D. W. (1966). Morphological changes in the brains of adult male rats after neonatal castration. Journal of Endocrinology, 36, 415-416.

Phillips, R. G., \& LeDoux, J. E. (1992). Differential contribution of amygdala and hippocampus to cued and contextual fear conditioning. Behavioral Neuroscience, 106, 274-285.

Philuips, R. G., \& LeDoux, J. E. (1994). Lesions of the dorsal hippocampal formation interfere with background but not foreground contextual fear conditioning. Learning \& Memory, 1, 34-44.

Roof, R. L. (1993). Neonatal exogenous testosterone modifies sex dif- 
ference in radial arm and Morris water maze performance in prepubescent and adult rats. Behavioural Brain Research, 53, 1-10.

ROOF, R. L., \& HAVENS, M. D. (1992). Testosterone improves maze performance and induces development of male hippocampus in females. Brain Research, 572, 310-313.

Schwartz, N. B., \& Hoffman, J. C. (1972). Ovulation: Basic aspects. In H. Balin \& S. Glasser (Eds.), Reproductive biology (pp. 438476). Amsterdam: Excerpta Medica.

Stewart, J., Skvarenina, A., \& Pottier, J. (1975). Effects of neonatal androgens on open-field behavior and maze learning in the prepubescent and adult rat. Physiology \& Behavior, 14, 291-295.

Stoehr, J. D., Markus, E. J., Nadel, L., \& Wenk, G. L. (1994). Effects of post-training intrahippocampal and amygdaloid injections of scopolamine on contextual and cued-fear conditioning. Society for Neuroscience Abstracts, 20, 149.

SUTHERLAND, R. J., \& RUDY, J. W. (1989). Configurational association theory: The role of the hippocampal formation in learning, memory, and amnesia. Psychobiology, 17, 129-144.

Teresawa, E., \& Timiras, P. S. (1968). Electrical activity during the estrous cycle of the rat: Cyclic changes in limbic structures. Endocrinology, 83, 207-216.

van Haaren, F., Wouters, M., \& van de Poll, N. E. (1987). Absence of behavioral differences between male and female rats in different radial-maze procedures. Physiology \& Behavior, 39, 409-412.

WADE, G. N. (1976). Sex hormones, regulatory behaviors, and body weights. In J. S. Rosenblatt, R. A. Hinde, E. Shaw, \& C. Beer (Eds.), Advances in the study of behavior (pp. 201-279). New York: Academic Press.

Warren, S. G., Humphreys, A. G., Juraska, J. M., \& Greenough, W. T. (1995). LTP varies across the estrous cycle: Enhanced synaptic plasticity in proestrous rats. Brain Research, 703, 26-30.
WARREN, S. G., \& JuRASKa, J. M., (1995), Place learning on the Morris water task does not reflect CA1 synaptic density changes across the estrous cycle. Society for Neuroscience Abstracts, 17, 1943.

WARREN, S. G., Wilson, L. A., \& NADEL, L. (1990). Sexually dimorphic spatial abilities in the Morris water task. Society for Neuroscience Abstracts, 16, 1321 .

Williams, C. L. (1996). Short-term but not long-term estradiol replacement improves radial-arm maze performance of young and aging rats. Society for Neuroscience Abstracts, 22, 1164.

Williams, C. L., Barnett, A. M., \& Meck, W. H. (1990). Organizational effects of early gonadal secretions on sexual differentiation in spatial memory. Behavioral Neuroscience, 104, 84-97.

Woolley, C. S. Gould, E., Frankfurt, M. \& McEwen, B. S. (1990). Naturally occurring fluctuation in dendritic spine density on adult hippocampal pyramidal neurons. Journal of Neuroscience, 10, 40354039.

WoOLLey, C. S., \& McEwEN, B. S. (1992). Estradiol mediates fluctuation in hippocampal synapse density during the estrous cycle in the adult rat. Journal of Neuroscience, 12, 2549-2554.

\section{NOTES}

1. Observers were not blind to the sex of the animals, since males are larger than females.

2. Note that Frye's definition of "behavioral estrus" corresponds to our proestrous stage.

(Manuscript received August 22, 1996; revision accepted for publication April 8, 1997.) 